\title{
Customers' evaluation of mechanical artificial intelligence in hospitality services: a study using online reviews analytics
}

Article

Accepted Version

Mariani, M. and Borghi, M. ORCID: https://orcid.org/00000002-4150-1595 (2021) Customers' evaluation of mechanical artificial intelligence in hospitality services: a study using online reviews analytics. International Journal of Contemporary Hospitality Management. ISSN 0959-6119 doi: https://doi.org/10.1108/IJCHM-06-2020-0622 Available at https://centaur.reading.ac.uk/98861/

It is advisable to refer to the publisher's version if you intend to cite from the work. See Guidance on citing.

To link to this article DOI: http://dx.doi.org/10.1108/IJCHM-06-2020-0622

Publisher: Emerald

All outputs in CentAUR are protected by Intellectual Property Rights law, including copyright law. Copyright and IPR is retained by the creators or other copyright holders. Terms and conditions for use of this material are defined in the End User Agreement. 


\section{CentAUR}

Central Archive at the University of Reading

Reading's research outputs online 


\section{Customers' Evaluation of mechanical Artificial Intelligence in Hospitality Services: A Study using Online Reviews Analytics}

Purpose-This work analyzes if and to what extent mechanical Artificial Intelligence (AI)embedded in hotel service robots-influences customers' evaluation of AI-enabled hotel service interactions. We deploy online reviews analytics to understand if the presence of mechanical AI-related text in online reviews influences customers' online review valence across 19 leading international hotels that have integrated mechanical AI - in the guise of service robots - into their operations.

Design/methodology/approach-First we identified the 19 leading hotels across three continents that have pioneered the adoption of service robots. Secondly, by deploying big data techniques, we gathered the entire population of online reviews (ORs) hosted on TripAdvisor (almost 50,000 ORs) and generated online review analytics. Subsequently, we employed ordered logistic regressions analyses to understand if and to what extent AI-enabled hospitality service interactions are evaluated by service customers.

Findings-The presence of mechanical AI-related text (text related to service robots) in online reviews (ORs) influences positively e-WOM valence. Hotel guests writing ORs explicitly mentioning their interactions with the service robots are more prone to associate high online ratings to their ORs. The presence of the robot's proper name (e.g., Alina, Wally) in the online review moderates positively the positive effect of mechanical AI-related text on online reviews ratings.

Research Implications/limitations-Hospitality practitioners should evaluate the possibility to introduce service robots into their operations and develop tailored strategies to name their robots (such as using human-like and short names). Moreover, hotel managers should communicate more explicitly their initiatives and investments in AI, monitor AI-related eWOM and invest in educating their non tech savvy customers to understand and appreciate AI technology. Platform developers might create a robotic tag to be attached to ORs mentioning service robots to signal the presence of this specific element, and might design and develop an additional service attribute that might be tentatively named "service robots".

Originality/value - The current work represents the first attempt to understand if and to what extent mechanical AI in the guise of hotel service robots influences customers' evaluation of AI-enabled hospitality service interactions.

Keywords: Artificial Intelligence; robot proper name; e-WOM; online review analytics; big data; TripAdvisor. 


\section{Introduction}

There is growing consensus among entrepreneurs and managers that Artificial Intelligence (AI) technologies are reaching a peak of inflated expectations (Gartner, 2019). AI is playing a paramount role in the digital transformation of both manufacturing (Rüßmann et al., 2015) and service industries (Mariani and Borghi, 2019) and is deeply affecting how organizations create and capture value (Huang and Rust, 2020). More specifically, AI technologies are taking over in services (Huang and Rust, 2018; 2020), thus modifying not only services operations but also service interactions (Wirtz et al., 2018).

Mechanical Artificial Intelligence (AI) in the guise of autonomous service robots (Huang and Rust, 2018) is bringing about a fourth industrial revolution also in the hospitality and tourism verticals (Tussyadiah, 2020). Over the last decade, service robots have been increasingly integrated in the operations of hotels worldwide, with the implicit or overt intention to achieve dual value through ambidextrous strategies of simultaneous cost reduction and service quality enhancement (Belanche et al., 2020a; Wirtz and Zeithaml, 2018). For instance, in the US, the Sheraton Los Angeles San Gabriel Hotel has recently introduced luggage, butler and concierge robots in their operations (Mills, 2018), whereas in Japan, the Henn-na Hotel is predominantly staffed with robots providing a fully automated service experience (Ivanov et al., 2019). This adoption process seems to have been catalyzed by the COVID-19 pandemic that has urged hotel managers to adopt service robots to better deal with social distance requirements (Zeng et al., 2020). Hotel customers, in their turn, are progressively accepting robots and interacting with them, though displaying differentiated reactions (Tuomi et al., 2020; Zhong et al., 2020). While the timing and ways of introduction of service robots in hotels' operations vary greatly across organizations (Ivanov et al., 2019), little is known about if and to what extent mechanical Artificial Intelligence - in the guise of service robots - influences customers' evaluation of and satisfaction with AI-enabled hospitality service interactions.

So far, most of the research revolving around service robots has been conceptual in nature. Among the few existing empirical studies covering consumers, the majority has focused on customer experiences captured by means of surveys. However, an unanswered question is: Do mechanical AI-enabled hospitality service interactions, as reported in online reviews, influence hotel customer evaluations of hotel services? To address this research question, this work builds on the intuition of Tung and Au (2018) who used online reviews (ORs) to assess customers' experience with robots. However, so far, scholars have not critically deployed robots-related text in online reviews (ORs) to derive insights on hotel online customers' 
evaluations and satisfaction. This is a remarkable research gap as hotel customers are becoming gradually more interested in technologies in general, and robots in particular, and it has been found that consumers' experiences are actually affected by services robots (Tung and Au, 2018).

The present study is unique because - to the best of our knowledge - it is the first to use the presence of mechanical AI-related text (namely the text related to service robots) in online reviews (ORs) to measure if and to what extent online customers' consideration of service robots affects customers' evaluation of and satisfaction with AI-enabled hospitality service interactions, whereby satisfaction is proxied by online review ratings (e.g., Engler et al., 2015). This approach builds on a recent study which indicated that ORs are an appropriate means to capture online consumers increasing awareness of (and discourse on) robots in hospitality (Borghi and Mariani, 2020). Moreover, it is also the first work to capture the moderating effect of the guest mentioning the proper rather than the general name of a robot on the effect of AIrelated text in ORs on OR valence. Accordingly, we make a unique contribution to the body of literature focusing on hotel customers' reactions to the introduction of robots (Belanche et al., 2020b; Tung and Au, 2018; Zhong et al., 2020) and more generally to the literature dealing with the effects and impact of mechanical AI on service customers (Huang and Rust, 2018; 2020).

After the sampling process, we identified the 19 most active pioneering international hotels making use of AI-enabled services across three continents, and we subsequently retrieved TripAdvisor online reviews (ORs) related to AI-enabled service interactions in hotels endowed with service robots. By deploying data analytics techniques, we then examined how the presence of robots-related text in online reviews (ORs) influenced customers' evaluation of and satisfaction with AI-enabled service interactions proxied by online review ratings (Engler et al., 2015). Accordingly, this study combines three research strands: (mechanical) AI in services, data analytics, and e-WOM, to make multiple contributions at the intersection of these three areas.

\section{Literature review}

\subsection{AI in Hospitality and Tourism}

There is general scholarly consensus that the first description of Artificial Intelligence (AI) appeared in science fiction almost eight decades ago in the writings of American science fiction writer Isaac Asimov. He published in 1942 his book Runaround which later became a source of inspiration for many scientists especially in the fields of computer science and robotics. The 
circumlocution Artificial Intelligence was officially coined in 1956 when American cognitive scientist Marvin Minsky and computer scientist John McCarthy hosted the Dartmouth Summer Research Project on Artificial Intelligence (DSRAI) at Dartmouth College, USA (Haenlein and Kaplan, 2019).

Over time, a number of scholars in business and management has recognized that AI has multiple ramifications. For instance, Davenport and Ronanki (2018) have distinguished three types of AI: process automation, cognitive insight and cognitive engagement. More recently, Huang and Rust (2020) have streamlined their former typology of AI in services (Huang and Rust, 2018), describing three forms of AI: mechanical, thinking and feeling. Mechanical AI, consistently with the previous definition developed in 2018 (Huang and Rust, 2018) relates to simple, standardized, repetitive, and routine tasks; thinking AI pertains to welldefined, systematic, complex, and rule-based tasks; feeling AI entails interactive, social, emotional, and communicative tasks. As clearly described by Huang and Rust (2018, 2020), robots are one typical application of mechanical AI. More specifically, service robots are "technology that can perform physical tasks, operate autonomously without needing instruction, and are directed by computers without help from people" (Colby et al., 2016). Service robots have been also defined as "system-based autonomous and adaptable interfaces that interact, communicate, and deliver service to an organization's customers." (Wirtz et al., 2018: 909). Despite the proliferation of definitions (Colby et al., 2016; Wirtz et al., 2018), scholars have emphasized that service robots embed technology for the purpose of delivering services to customers.

Service robots are becoming increasingly popular across several service industries and most notably in hospitality and tourism services (Tuomi et al., 2020; Tussyadiah, 2020). Among the latter industries, hotels are increasingly integrating AI into their operations (Ivanov et al., 2017, 2019). For instance, hotels are witnessing an increasing adoption of service robots and it is expected that robots will constitute about $25 \%$ of the workforce in the hospitality sector by 2030 (Bowen and Morosan, 2018), thus radically compressing labor costs while allowing to achieve differentiation and customization (Wirtz and Zeithaml, 2018).

In their recent literature review on robotics in hospitality and tourism, Ivanov et al. (2019) clustered extant literature into seven key broad research domains: Robot, Human, Robot manufacturer, Travel/tourism/hospitality company, Servicescape, External environment, and Education, training and research. While suggesting that robotics in hospitality and tourism is not a mature field, lacking strong empirical research, they observed that, while the robot design is the most prominent theme, there "is a lot less research that considers the demand/human 
side, especially the impacts of robots on the tourism and hospitality experience..." (Ivanov et al., 2019: 507). Within the tiny research stream focusing on customers' perceptions of robots, there is a handful of studies that have focused on customer intention, satisfaction, and service quality evaluations (Belanche et al., 2020a; Rodriguez-Lizundia et al., 2015; Tung and Law, 2017; Tung and $\mathrm{Au}, 2018, \mathrm{Yu}, 2018$ ). For instance, Rodriguez-Lizundia et al. (2015) examined through experiments user engagement of humans interacting with a bellboy robot and found that robot embodiment (i.e., the presence of a robotic body), awake status of the robot named Sacarino, and proactivity in starting a conversation were positively related to user engagement. Tung and Law (2017) reviewed in depth work in robotics and explored conceptually humanrobot interactions (HRIs), especially in relation to the dimensions of presence and embodiment, suggesting that more research would be needed in the area of the influence of service robots on the tourist experience. Yu (2018) measured customers' perceptions of service robots comparing consumers from individualist vs. collectivist background and found that perceived customer satisfaction depends on cultural background. Tung and Au (2018) examined through an exploratory study how online reviewers appraise their experiences during human-robot interactions (HRIs) and found that human-oriented perceptions and robotic embodiment influenced consumer experiences. Building on attribution theory and technology acceptance models, Belanche et al. (2020a) examined 517 customers assessing service robots and found that attributions mediate the relationships between affinity toward the robots and customer behavioral intentions to use and recommend service robots. By conducting an experiment, Zhong et al. (2020) found that the purchase intention of subjects that were exposed to the video of a robot-empowered hotel service were significantly higher than those exposed to the video portraying a traditional hotel service. Leveraging on online reviews, Borghi and Mariani (2020) found that service robots are a distinctive and popular attribute in the evaluation of the hotel stay. Moreover, the authors developed the novel concept of online robotic discourse - "defined as eWOM in online reviews mentioning explicitly service robots deployed in hospitality services" - (Borghi and Mariani, 2020: p.2) which can aid researchers to effectively monitor the diffusion and adoption of service robots over time.

To summarize, the nascent research stream revolving around customers' perceptions of robots, has mainly examined how customers' perceptions might change in light of robots' features (Rodriguez-Lizundia et al., 2015) and customers' demographics (Yu, 2018). However, as recently noted by Lu et al. (2020) and Tussyadiah (2020), empirical studies examining the impact of service robots on customers are somehow scarce and multiple research gaps are left unbridged. More specifically, scholars (Lu et al., 2020; Tussyadiah, 2020), have recently called 
for more empirical research on service robots in hospitality and tourism, given that most of the extant research is conceptual in nature (Wirtz et al., 2018). We recognize this research gap and answer that call by exploring if and to what extent mechanical Artificial Intelligence, embedded in hospitality service robots, influences consumers' evaluation of AI-enabled hotel service interactions. In line with Borghi and Mariani (2020), we recognize that the concept of online robotic discourse can be useful to conduct our investigation. More specifically, we deploy online reviews analytics to understand if robots-related text in online reviews has an effect on customers' electronic Word-of-Mouth valence across 19 leading international hotels that have integrated mechanical AI, in the guise of service robots, into their operations.

\subsection{Deploying analytics from Online Reviews to shed light on AI-enabled services}

\subsubsection{Online Reviews Analytics}

The advent and development of online review (OR) platforms in hospitality and tourism has ushered the generation and growth of large volumes of user generated content (UGC) in the guise of ORs of hospitality and tourism services. Several scholars have observed that those ORs can be retrieved and analyzed by means of Big Data (BD) technologies (Laney, 2001) that allow to capture and analyze large Volumes of data generated at high Velocity displaying a high Variety of formats (the so called " $3 \mathrm{Vs}$ " of BD). BD is therefore particularly relevant in today's digitized hospitality sector (Li et al., 2018; Mariani et al., 2018; Mariani, 2019), and constitutes the raw material needed to engender BD analytics (BDA). The latter refers to a holistic process aimed to retrieve, preprocess, process, clean, analyze, visualize, report, and interpret BD with the aim of generating business insights conducive to the creation of business value (Fosso Wamba et al., 2015). Those firms able to effectively master BDA, might eventually gain enhanced competitive performance (Mariani and Fosso Wamba, 2020). Within the hospitality sector, BDA are generated from various sources including UGC data, operations in the form of transaction data, and devices in the guise of device data. The first form of data - UGC data - is perhaps the most widespread and has been consistently deployed by hospitality scholars in the form of social media posts and ORs. The latter ones, and the derived analytics, have been instrumental to gain insights on online customer engagement (e.g., Xu et al., 2020), experiences (e.g., Tung and $\mathrm{Au}, 2018$ ), and satisfaction (e.g., Mariani, Di Fatta and Di Felice, 2018; Zhou et al., 2014) with hospitality services.

The literature on big data and analytics in hospitality and tourism is increasing but rather fragmented (Mariani et al., 2018; Mariani, 2019). Due to space constraints, we redirect the reader to systematic literature reviews (Li et al., 2018; Mariani et al., 2018) for more details. 


\subsection{2 e-WOM valence, customer satisfaction and mechanical AI}

The growth of digital platforms has triggered an outburst of online reviews (ORs). ORs represent a digitized medium that current and former online customers deploy to articulate, express and share their perceptions and evaluations about goods and services, as well as companies and brands on the Internet (Hennig-Thurau et al., 2004). Accordingly, the level of customer satisfaction with a product or service will determine the level of online review ratings, and therefore online review ratings are a good proxy of customer satisfaction with the goods/services that were consumed (e.g., Engler et al., 2015). Examined in depth in a variety of disciplines and fields including information management (i.e., Dellarocas et al., 2010), computer science (i.e., Titov and McDonald, 2008) and marketing (i.e., You et al., 2015), ORs have progressively given rise to a new stream of literature termed as electronic Word-Of-Mouth (e-WOM). In today's consumer markets, consumer engagement and purchase intentions are deeply influenced by e-WOM which constitutes the second most important and credible source of information before a purchase after traditional WOM (Chu and Kim, 2011; Ludwig et al. 2013; Zhu and Zhang 2010). E-WOM literature has recorded a significant expansion over time (King et al., 2014) and more generally in the last fifteen years. This is because differently from traditional WOM e-WOM is characterized by increasingly relevant features that entail convenience, one-to-many and many-to-many reach, rapidity of diffusion, lack of face-to-face interaction, communication effectiveness, and potential anonymity (Sun et al., 2006). Scholars have dealt with both the drivers (or antecedents) and consequences (or outcomes) of e-WOM in marketing (e.g., Rosario et al., 2016). In this work, consistently with the cited studies, the terms ORs and e-WOM are used interchangeably.

The ubiquity of e-WOM in the hospitality sector is rather evident (Litvin et al., 2008) and is related to the growing volume of ORs produced and scrutinized by a multitude of online users of online travel review platforms (i.e., TripAdvisor), e-commerce platforms (i.e., Expedia), and generalist social media platforms (i.e., Facebook). E-WOM has been found to prompt hotel services consumers' purchasing and booking intentions (Cezar and Ogut, 2016) and influence eventually sales (Blal and Sturman, 2014) and hotels' financial performance (Mariani and Borghi, 2020).

E-WOM extracted from the analysis of ORs is sought by consumers as a valuable source of information prior to making purchase decisions since hotel services' quality is not assessable and often unknown prior to consumption (Litvin et al., 2008). As an example, ORs stemming from TripAdvisor are commonly exploited by online prospective customers in their 
decision-making process and ORs ratings have been found to positively influence online bookings (Cezar and Ogut, 2016). Therefore, large volumes of ORs constitute both a relevant source for informing hospitality companies' strategy and business intelligence (Mariani et al., 2018) and a critical means to produce vital metrics on online consumers' perceptions (Xu and $\mathrm{Li}, 2016)$ and online satisfaction.

As mentioned above, a number of hotels have integrated mechanical AI (Huang and Rust, 2018), in the guise of service robots, into their operations over the last decade. This has triggered online consumers increasing awareness of (and discourse on) robots in the text of their online reviews (Borghi and Mariani, 2020). While the nascent research stream revolving around customers' perceptions of robots, has mainly examined how customers' perceptions might change in light of robots' features (Rodriguez-Lizundia et al., 2015) and used ORs to describe guests' experiences (Tung and Au, 2018), no empirical research has shed light on whether and to what extent mechanical Artificial Intelligence, embedded in hospitality service robots, influences consumers' evaluation of AI-enabled hotel service interactions. Accordingly, the research question we decided to address is the following one:

RQ: Do mechanical AI-enabled hospitality service interactions, as reported in online reviews, influence hotel customer evaluations of hotel services?

Based on the aforementioned research question and underpinning literature, we move a step further and develop two research hypotheses. Service robots have been found to enhance hotel customers' experiences (Tung and $\mathrm{Au}, 2018$ ) also because they can inject elements of entertainment into hospitality services (Ivanov and Webster, 2019), thus making the experience even more compelling and appealing (Pine and Gilmore, 1998). As superior experiences with service robots have been empirically found to generate service perceptions exceeding service expectations (Stock and Merkle, 2017), we can conjecture that when mechanical AI-enabled service interactions are explicitly mentioned in hotel guests' online evaluations, they will translate into customer satisfaction and therefore positively affect e-WOM valence, as a proxy of online customer satisfaction (Engler et al., 2015). Accordingly, we hypothesize that:

H1: The presence of e-WOM covering mechanical AI-enabled hospitality service interactions influences positively e-WOM valence in the guise of online review ratings.

Established social psychology literature (e.g., Gutek et al., 1999) has suggested that service interactions display different degrees of depth and that a subset of service interactions typically named service encounters - lead to develop service relationships. In parallel, recent 
service literature has emphasized the role of identifying and recalling the proper names of the service providers and/or frontline employees (Belanche et al., 2020d) to empower service encounters in the eyes of the customers (Kim and Baker, 2017). We argue that also humanrobot interactions display different degrees of depth and only a subset of those human-robot interactions display the features of a service relationship. They are those where the customer remembers some features (e.g., the appearance or even the proper name) of the robot. More specifically, if a hotel guest only remembers that s/he had an interaction with a robot, without recalling the robot's proper name (for instance saying "The robot was another interesting idea the children liked" or "I loved the fact that a robot could deliver things like water or toothpaste to your room"), it is likely that the service interaction was not deep enough and did not lead to the development of a service relationship. On the other hand, if a hotel guest remembers that $\mathrm{s} /$ he had an interaction with a robot, recalling explicitly the robot's proper name and writing that name in her/his online review (for instance saying "And a visit from ["Robot proper name"], the hotel robot, was a fun surprise for my wife." or "Some things we did LOVE: The ["Robot proper name"] was a hit with my children!"), then it is very likely that the service interaction was rather deep and became a service relationship, involving the creation of a rapport between the hotel guest and the robot (Wirtz et al., 2018) and translating into higher levels of engagement, better overall experience (Tung and Au, 2018) and ultimately into higher levels of satisfaction. In a more nuanced appreciation, mentioning or recalling explicitly the robot proper name might mirror higher customer attention and interest that might ultimately amplify the effect of the presence of the robot on customer satisfaction. Accordingly, we hypothesize that the recall of the robot's proper name when writing a review has a positive moderation effect on the positive relationship between the presence of the robot in the online review and online review ratings. Therefore, we hypothesize that:

H2: The presence of the proper name of the robot in e-WOM covering mechanical AI-enabled hospitality service interactions strengthens the positive effect of the presence of e-WOM covering mechanical AI-enabled hospitality service interactions on e-WOM valence in the guise of online review ratings. 
Figure 1- Research Model

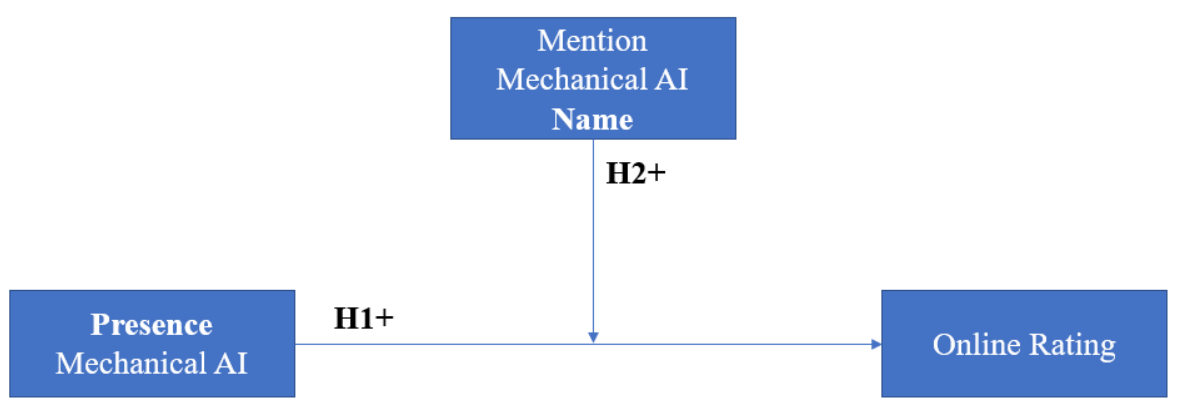




\section{Methodology}

\subsection{Data and sample}

With the aim of investigating the impact of mechanical AI-enabled service interactions on reviewing guests' online review ratings we leveraged a large sample of online review data from a set of international hotels implementing AI-enabled hospitality services in their operations. As far as the OR platform is concerned, we decided to collect OR data from TripAdvisor since it is widely recognized as a popular platform among online travellers and it has been used extensively in the hospitality and tourism research domain (e.g., Gao et al., 2018; Phillips et al., 2020; Zhao et al., 2019).

The sample selection process was developed in two phases: 1) identification of leading international hotels deploying AI-enabled services in their day-to-day activities and 2) collection of TripAdvisor OR data for the companies identified in step 1. To identify leading hotels deploying AI-enabled services in their operations we deployed the sampling process developed and described by Inversini et al. (2010). First, we conducted a series of online searches through Google navigating until the third page in the browser. More specifically, we created our online research queries combining the keyword "hotel" with the set of service robots related keywords suggested by Ivanov et al. (2017), which identify the roles assumed by service robots in the hotel industry (i.e., robot concierge, robot luggage, etc.). After this extensive online research, we manually explored the online sources obtained from the queries' results to identify whether international hotels which have adopted mechanical AI in the guise of hospitality service robots where mentioned. From the latter we created a preliminary list of potential candidate hotels for our final sample and we gathered external sources of information for each of the businesses singled out (i.e., company reports, company news, website, and social media materials). As such, triangulating the different resources collected, we were able to acquire specific subject knowledge on the implementation of mechanical AI-enabled service interactions, such as the moment when the robot was introduced and whether or not a name was associated with the machine. From this preliminary sample we only selected hotels which had a TripAdvisor account and for which we were able to understand the specific period for the deployment of service robots. We selected TripAdvisor because it is considered the largest online review platform, covering an extensive number of service evaluations (e.g., Bi et al., 2019). This led the research team to identify 19 international hotels, located in three continents, whose details are presented in Table 1. Secondly, for each hotel recognized in the first research step, we collected the entire set of ORs displayed in the hotels' TripAdvisor profile until 
October 2019. During the OR data collection process, we captured quantitative features related to the OR, such as the overall review rating, as well as unstructured features, such as the review text, in order to discern whether a mechanical AI-enabled service interaction was mentioned by the reviewing guests. Besides, for each OR we collected reviewer-level information and hotel-level information to conduct a more comprehensive analysis.

After having collected the entire population of TripAdvisor OR data, totalling 49,209 reviews, we performed a set of data cleaning tasks. To this aim, firstly, in line with other studies analysing the written content of ORs, we removed all the non-English ORs. Secondly, we retained only ORs that were written after the introduction of mechanical AI (i.e., service robots) within hotels' operations as it is only after the moment when they were introduced that robots are more likely to interact with hotel guests and influence their satisfaction with hotel services. Consequently, the final sample used for our study entails 21,616 online reviews that were embedded in our econometric models.

Table 1 - Sample of hotels

\begin{tabular}{|l|l|l|}
\hline Hotel ID & \multicolumn{1}{|c|}{ Hotel Location } & \multicolumn{1}{|c|}{$\begin{array}{c}\text { Type of Mechanical } \\
\text { AI-enabled service } \\
\text { interaction }\end{array}$} \\
\hline Hotel 1 & Cupertino (USA) & butler \\
\hline Hotel 2 & San Jose (USA) & butler \\
\hline Hotel 3 & Los Angeles (USA) & butler \\
\hline Hotel 4 & Sasebo (Japan) & $\begin{array}{l}\text { front desk, luggage, room } \\
\text { assistant, concierge, butler }\end{array}$ \\
\hline Hotel 5 & Tysons (USA) & concierge \\
\hline Hotel 6 & Chicago (USA) & butler \\
\hline Hotel 7 & Singapore (Republic of Singapore) & butler \\
\hline Hotel 8 & New York (USA) & butler \\
\hline Hotel 9 & Singapore (Republic of Singapore) & butler, chef \\
\hline Hotel 10 & Munich (Germany) & concierge \\
\hline Hotel 11 & Singapore (Republic of Singapore) & butler \\
\hline Hotel 12 & Temecula (USA) & security \\
\hline Hotel 13 & Los Angeles (USA) & butler \\
\hline Hotel 14 & San Gabriel (USA) & butler, luggage, concierge \\
\hline Hotel 15 & Singapore (Republic of Singapore) & butler \\
\hline Hotel 16 & Las Vegas (USA) & butler \\
\hline Hotel 17 & Boston (USA) & butler \\
\hline Hotel 18 & New York (USA) & luggage \\
\hline Hotel 19 & Singapore (Republic of Singapore) & butler \\
\hline
\end{tabular}

\subsection{Variables}

Dependent Variable: in the study we used the overall rating provided by the online reviewer as dependent variable. This measure can be seen as a proxy of the perceived overall satisfaction 
of the reviewing guest with the hotel services during her stay (Engler et al., 2015). In particular, in TripAdvisor this metric can assume five values in the following ordinal categorical scale: "Terrible"=1, "Poor"=2, "Average"=3, "Very Good"=4, "Excellent"=5.

Focal Independent Variables: To explore the relationship between mechanical AI service interactions and online review ratings, we leveraged a focal independent variable that we labelled Presence Mechanical AI as a shorter circumlocution to indicate the presence of Mechanical AI enabled service interactions. Essentially, as argued by Bi et al. (2019) ORs can be seen as a mixture of topics that are identifiable through specific keywords. More specifically, Bi et al. (2019) suggest and prove that looking for a specific set of keywords inside the textual content of online reviews allows researchers to understand the specific attributes the reviewer referred to, and ultimately evaluated. Accordingly, and in line with the extant study of Tung and Au (2018), we used the keyword "robot" combined with the machine proper name (if it had one) to identify whether or not the reviewer referred to a mechanical AI-enabled service interaction in her overall judgement of the stay. More specifically, the existence of the keyword "robot" was inspected inside the entire text (i.e., all the words) of the review, to include also those words whose morphological root is the term "robot" (Booij, 2012). This allowed us to take into account reviews containing "robot*" words. Thus, Presence Mechanical $A I$ is operationalized as a dummy variable equal to one if the review text embedded at least one of the aforementioned keywords, and zero otherwise. To ensure further validity of our focal explanatory variable, after the automatic search, the research team performed a manual check of all the ORs to guarantee that service robots were actually mentioned. Therefore, this step allowed us to remove from this category those ORs that used AI-related keywords to describe occurrences different from a mechanical AI-enabled service interaction. For instance, we set Presence Mechanical AI to zero for those ORs where the reviewer used the term "robotic" to depict a not particularly engaging experience with human front line employees. Accordingly, combining the automatic search with the manual consistency check, we were able to clearly identify reviewers mentioning explicitly mechanical AI. We also created a second dummy variable, Mention Mechanical AI Name, equal to one if the reviewing guest mentioned the proper name of the robot (e.g., Alina, Wally, Yolanda, etc.) in the OR. We used this variable to test the second hypothesis of the study.

Control Variables: In order to ensure robustness to our analysis, we integrate into the econometric models several control variables consistently with the latest studies deploying eWOM data (Bi et al., 2020; Gao et al., 2018; Mariani et al., 2019; Mariani, Borghi \& Gretzel, 2019; Xu et al., 2020; Zhang et al., 2016). Table 2 summarizes the set of variables used in the 
econometric model providing their description, while Table 3 illustrates their descriptive statistics.

Table 2 - Variables description

\begin{tabular}{|c|c|}
\hline Variable & Description \\
\hline Review Rating & $\begin{array}{l}\text { Overall Rating provided by a reviewing guest to synthesize } \\
\text { her overall satisfaction with the stay. }\end{array}$ \\
\hline Presence Mechanical AI & $\begin{array}{l}\text { It is a dummy variable equal to } 1 \text { when the online reviewer } \\
\text { refers to mechanical AI in the guise of hospitality service } \\
\text { robots in her review. }\end{array}$ \\
\hline Mention Mechanical AI Name & $\begin{array}{l}\text { It is a dummy variable equal to } 1 \text { when the reviewing guest } \\
\text { mentioned the proper name (e.g., Alina, Wally, Yolanda, } \\
\text { etc.) of the robot in her review. }\end{array}$ \\
\hline \multicolumn{2}{|l|}{ Control Variables } \\
\hline Observed Average Rating & $\begin{array}{l}\text { Rating observed by the online reviewer prior to submit her } \\
\text { own review. }\end{array}$ \\
\hline Reviewer Experience & $\begin{array}{l}\text { It corresponds to the number of contributions provided by } \\
\text { the online reviewer in the OR platform. }\end{array}$ \\
\hline Identity Disclosure & $\begin{array}{l}\text { It is operationalized as a dummy variable that assumes the } \\
\text { value of } 1 \text { if the reviewer disclosed her age or gender, and } \\
\text { zero otherwise. }\end{array}$ \\
\hline Reviewing Effort & The number of words included in an online review. \\
\hline Travel Type & $\begin{array}{l}\text { It is a categorical variables which embeds } 5 \text { different } \\
\text { options: Couple, Solo, Family, Business and Group. }\end{array}$ \\
\hline Mobile Submission & $\begin{array}{l}\text { It is a dummy variable that is equal to } 1 \text { if the review has } \\
\text { been written using a mobile device, and zero otherwise }\end{array}$ \\
\hline Year & It represents the year in which the review has been written. \\
\hline Chain & $\begin{array}{l}\text { A dummy variable that is equal to } 1 \text { if the hotel is part of a } \\
\text { chain company and zero otherwise. }\end{array}$ \\
\hline Star Rating & $\begin{array}{l}\text { Categorical metric that depicts the hotel star rating category } \\
\text { (from } 1 \text { - to } 5 \text {-stars). }\end{array}$ \\
\hline Hotel ID & $\begin{array}{l}\text { It represents an unique identifier for each hotel analysed. It } \\
\text { is operationalized as a set of dummy variables in the } \\
\text { econometric model. }\end{array}$ \\
\hline
\end{tabular}


Table 3 - Descriptive statistics

\begin{tabular}{lllll}
\hline & Mean/Proportion & SD & Min & Max \\
\hline Review Rating & 4.259 & 1.035 & 1 & 5 \\
Presence Mechanical AI & 0.137 & & 0 & 1 \\
Mention Mechanical AI Name & 0.046 & & 0 & 1 \\
Observed Average Rating & 4.318 & 0.164 & 3.2 & 5.0 \\
Log(Reviewer Experience) & 2.175 & 1.869 & 0 & 11.703 \\
Identity Disclosure & 0.291 & & 0 & 1 \\
Log(Reviewing Effort) & 4.424 & 0.713 & 1.792 & 7.610 \\
Mobile Submission & 0.232 & & 0 & 1 \\
\hline Observations & 21,616 & & & \\
\hline
\end{tabular}

\subsection{Model Specification}

In order to model the relationship between the presence of mechanical AI-enabled service interactions and the overall review rating we deployed an econometric model able to take into account the nature of our dependent variable (Review Rating) which is an ordinal categorical variable. As suggested by Agresti (2010) the appropriate model is an ordinal regression one. In fact, leveraging on linear regression approaches (such as Ordinary Least Square) could have provided biased estimation results, mainly because they do not take into account what has been labelled as the "floor" and "ceiling" effects which are - by definition - embedded in ordinal dependent variables (Agresti, 2010). In particular, in line with extant literature analyzing review ratings (Gao et al., 2018; $\mathrm{Hu}$ and $\mathrm{Li}, 2011$; Zhang et al., 2016), we assumed a logistic distribution for the error term, which led us to utilize an ordered logit model to verify our main hypotheses.

More formally, denoting with $y_{i j}^{*}$ the underlying latent variable representing the latent overall rating provided by reviewer $i$ for hotel $j$, we estimated the following econometric specification:

$$
\begin{aligned}
& y_{i j}^{*}=\beta_{1} \text { Presence Mechanical } A I_{i j}+\beta_{2} \text { Mention Mechanical AI Name }{ }_{i j}+ \\
& \beta_{3} \text { Observed Average Rating }_{i j}+\beta_{4} \text { Reviewer Experience }_{i}+ \\
& \beta_{5} \text { Identity Disclosure }_{i}+\beta_{6} \text { Mobile Submission }_{i j}+ \\
& \beta_{7} \text { Reviewing Effort }_{i j}+\beta_{8} \text { Chain }_{j}+\theta_{1}^{\prime} \text { Travel Type }_{i j}+\theta_{2}^{\prime} \text { Year }_{i j}+ \\
& \theta_{3}^{\prime} \text { Star Rating } j+\theta_{4}{ }^{\prime} \text { Hotel } I D_{j}+\epsilon_{i j}
\end{aligned}
$$

where $\epsilon_{i j}$ refers to the error term at the single review level and, $\beta_{i}$ and $\theta_{i}$ indicate the regression coefficients and vector of coefficients, respectively. 
In equation (1) to test the focal hypotheses of the manuscript we are mainly interested in the coefficient $\beta_{1}$ and $\beta_{2}$ which refer to the impact of reviewers mentioning respectively the presence of mechanical AI-enabled service interactions and the robot's proper name (e.g., Alina, Wally, Yolanda, etc.), on the reviewers' overall rating of the hotel stay. All the other regressors are included in the econometric model as control variables since they have already been found in extant literature to potentially act as antecedents of the review valence. Finally, due to the skewness of Reviewing Effort and Reviewer Experience distributions, we used their logarithmic form in the estimations.

\section{Findings and discussions}

As far as the estimation results are concern, Table 4 presents in a hierarchical fashion the findings stemming from the econometric analysis. In particular, Model 1 inspects the effect of "Presence Mechanical AI" using only the hotel and time fixed effects as control variables. In addition, Model 2 includes the entire set of control variables without robot-related metrics, whereas Model 3 takes into account both the independent variables of the aforementioned models. Finally, the full econometric specification stated in equation (1), including the interaction effect of Presence Mechanical AI and Mention Mechanical AI Name, is tested in Model 4. It is interesting to notice that in all the four models proposed, the effect of the focal independent variable "Presence Mechanical $A I$ " is constantly positive and statistically significant $(\mathrm{p}<0.001)$, thereby suggesting a positive and not negligible impact of mechanical $\mathrm{AI}$ in the guise of service robots in the overall evaluation of the hotel stay. In other words, in relation to the interaction with AI-enabled services, guests' interactions with mechanical AI seem to add value which translates into higher levels of overall customer satisfaction in the guise of online review ratings. Indeed, more formally, looking at the magnitude of the coefficient in Model 4 (the more specified), for ORs explicitly mentioning mechanical AIenabled service interactions we expect a 0.269 increase in the log odds of being in a higher rating category. Put simply, when mechanical AI is taken into account by hotel guests in their online evaluations, it increases the likelihood of the OR being associated with a higher rating category. This, in turn, implies that reviewers are satisfied with mechanical AI. Thus, we can infer a positive and significant association between mechanical AI in the guise of service robots and online ratings, which supports our first research hypothesis. This finding corroborates extant conceptual (Ivanov and Webster, 2019) and qualitative research (Stock and Merkle, 
2017; Tung and Au, 2018) that suggests, without any quantitative empirical tests, that AIenabled services can enhance guest experiences.

In relation to the interaction effect of Presence Mechanical AI and Mention Mechanical AI Name, as clear from Model 4 in Table 4 the coefficient is positive and statistically significant $(\mathrm{p}<0.001)$. Accordingly, our second hypothesis is supported, suggesting that the presence of the proper name of the robot strengthens the positive effect of the presence of e-WOM covering mechanical AI-enabled hospitality service interactions on online review ratings. This suggests that when a reviewer recalls the name of the robot, s/he has likely developed a service relationship during her/his hotel which goes far beyond a mere service interaction (e.g. Gutek et al., 1999). This suggests that recalling the proper name of mechanical AI, very much like recalling a proper name of a frontline employee (Kim and Baker, 2017) equates to recalling a memorable experience with the robot (Tung and $\mathrm{Au}, 2018$ ) which contributes to enhance service excellence (Wirtz et al., 2018) and ultimately to increase customer satisfaction with mechanical AI.

In terms of the main control variables, the results are in line with extant literature in hospitality and tourism. In particular, the rating observed in the hotel profile page is found to be positively and significantly $(\mathrm{p}<0.001)$ influencing reviewing behaviours, in line with Gao et al. (2018). On the contrary, the expertise of the reviewer and the reviewing effort have a negative and statistically significant effect $(\mathrm{p}<0.001)$ on the overall rating (Zhang et al., 2016; Zhao et al., 2019). In addition, identity disclosure is not found to influence reviewers' judgment of the stay, in line with previous studies (Sridhar and Srinivasan, 2012). This finding seems to be in contrast with other literature that has suggested that online community members sharing identity-related information might affect ORs (Forman et al., 2008). However, in line with Munzel (2016), identity disclosure helps the reader of the review to evaluate the review's source as trustworthy but does not suggest a clear direction in terms of online review ratings. Furthermore, in line with extant studies (e.g., Mariani et al., 2019), business travellers provide the more negative evaluations. As depicted by Bi et al. (2020) this could be due to the fact that consumers with different travel types prioritize a diverse set of attributes in their judgements revolving around their stay.

As far as the negative effect of reviewer experience on online ratings is concerned, the finding is consistent with previous research in hospitality (Mariani and Predvoditeleva, 2019) suggesting that as the status as an expert strengthens, experienced reviewers self-conceptualize themselves as experts and opinion leaders and as a consequence they could become more critical and therefore post more conservative reviews (Zhang et al., 2016). Regarding the 
reviewing effort, the longer the review, the more likely is that the reviewer is complaining (Sridhar and Srinivasan, 2012).

Table 4 - Estimation results Ordered logistic models

\begin{tabular}{|c|c|c|c|c|c|}
\hline & & $\begin{array}{l}\text { Model } \\
\text { (1) }\end{array}$ & $\begin{array}{l}\text { Model } \\
\text { (2) }\end{array}$ & $\begin{array}{l}\text { Model } \\
\text { (3) }\end{array}$ & $\begin{array}{l}\text { Model } \\
\text { (4) }\end{array}$ \\
\hline Presence Mechanical AI & H1 & $\begin{array}{c}0.136^{* * *} \\
(0.040)\end{array}$ & & $\begin{array}{l}0.425^{* * *} \\
(0.043)\end{array}$ & $\begin{array}{c}0.269^{* * *} \\
(0.050)\end{array}$ \\
\hline Presence Mechanical AI * & H2 & & & & $0.491^{* * 8}$ \\
\hline Mention Mechanical AI Name & & & & & $(0.083)$ \\
\hline Observed Average Rating & & & $\begin{array}{l}1.634^{* * 8} \\
(0.220)\end{array}$ & $\begin{array}{l}1.557^{* * *} \\
(0.220)\end{array}$ & $\begin{array}{l}1.555^{* * *} \\
(0.221)\end{array}$ \\
\hline Identity Disclosure & & & $\begin{array}{l}-0.003 \\
(0.035)\end{array}$ & $\begin{array}{c}-0.003 \\
(0.0355)\end{array}$ & $\begin{array}{l}-0.004 \\
(0.035)\end{array}$ \\
\hline Log (Reviewer Experience) & & & $\begin{array}{c}-0.037^{* * 8} \\
(0.009)\end{array}$ & $\begin{array}{c}-0.039^{* * *} \\
(0.009)\end{array}$ & $\begin{array}{c}-0.038^{* * 8} \\
(0.009)\end{array}$ \\
\hline Mobile Submission & & & $\begin{array}{l}-0.047 \\
(0.035)\end{array}$ & $\begin{array}{l}-0.050 \\
(0.035)\end{array}$ & $\begin{array}{l}-0.047 \\
(0.035)\end{array}$ \\
\hline Log (Reviewing Effort) & & & $\begin{array}{c}-0.680^{* * 8} \\
(0.022)\end{array}$ & $\begin{array}{c}-0.716^{* * *} \\
(0.022)\end{array}$ & $\begin{array}{c}-0.723^{* * *} \\
(0.022)\end{array}$ \\
\hline Traveled on business & & & $\begin{array}{c}-0.505^{* * *} \\
(0.038)\end{array}$ & $\begin{array}{c}-0.496^{* * 8} \\
(0.038)\end{array}$ & $\begin{array}{c}-0.494^{* * 8} \\
(0.038)\end{array}$ \\
\hline Traveled solo & & & $\begin{array}{c}0.087 \\
(0.054)\end{array}$ & $\begin{array}{l}0.103^{*} \\
(0.054)\end{array}$ & $\begin{array}{l}0.100^{*} \\
(0.054)\end{array}$ \\
\hline Traveled with family & & & $\begin{array}{l}-0.085^{*} \\
(0.038)\end{array}$ & $\begin{array}{l}-0.101^{* 8} \\
(0.038)\end{array}$ & $\begin{array}{l}-0.100^{* 8} \\
(0.038)\end{array}$ \\
\hline Traveled with friends & & & $\begin{array}{l}-0.036 \\
(0.050)\end{array}$ & $\begin{array}{l}-0.039 \\
(0.050)\end{array}$ & $\begin{array}{l}-0.038 \\
(0.050)\end{array}$ \\
\hline Further Controls: & & & & & \\
\hline $\begin{array}{l}\text { Year Dummies } \\
\text { Chain }\end{array}$ & & $\begin{array}{l}\text { Included } \\
\text { Included }\end{array}$ & $\begin{array}{l}\text { Included } \\
\text { Included }\end{array}$ & $\begin{array}{l}\text { Included } \\
\text { Included }\end{array}$ & $\begin{array}{l}\text { Included } \\
\text { Included }\end{array}$ \\
\hline Star Rating & & Included & Included & Included & Included \\
\hline Hotel ID & & Included & Included & Included & Included \\
\hline Intercept-1 & & $\begin{array}{c}-2.599^{* * 8} \\
(0.209)\end{array}$ & $\begin{array}{c}-0.262 \\
(0.840)\end{array}$ & $\begin{array}{l}-0.723 \\
(0.843)\end{array}$ & $\begin{array}{l}-0.780 \\
(0.843)\end{array}$ \\
\hline Intercept-2 & & $\begin{array}{c}-1.823^{* * *} \\
(0.208)\end{array}$ & $\begin{array}{c}0.530 \\
(0.840)\end{array}$ & $\begin{array}{l}0.0703 \\
(0.843)\end{array}$ & $\begin{array}{l}0.0145 \\
(0.842)\end{array}$ \\
\hline Intercept-3 & & $\begin{array}{c}-0.949^{* * 8} \\
(0.208)\end{array}$ & $\begin{array}{l}1.438^{*} \\
(0.840)\end{array}$ & $\begin{array}{c}0.981 \\
(0.843)\end{array}$ & $\begin{array}{c}0.926 \\
(0.842)\end{array}$ \\
\hline Intercept-4 & & $\begin{array}{l}0.515^{*} \\
(0.207)\end{array}$ & $\begin{array}{c}2.987^{* * *} \\
(0.840)\end{array}$ & $\begin{array}{l}2.537^{* *} \\
(0.843)\end{array}$ & $\begin{array}{l}2.483^{* *} \\
(0.842)\end{array}$ \\
\hline Observations & & 21,616 & 20,166 & 20,166 & 20,166 \\
\hline Pseudo $R^{2}$ & & 0.050 & 0.127 & 0.130 & 0.132 \\
\hline AIC & & $49,388.9$ & $44,708.1$ & $44,612.5$ & $44,579.2$ \\
\hline LR Chi2 & & $837.1^{* * 8}$ & $2,213.0^{* * *}$ & $2,310.5^{* * *}$ & $2,345.9^{* * *}$ \\
\hline Log Likelihood & & $-24,663.5$ & $-22,315.0$ & $-22,266.3$ & $-22,248.6$ \\
\hline
\end{tabular}

Notes: Standard errors in parentheses. Models 2, 3 and 4 have slightly less observations due to

missing values related to the Travel Type measure. ${ }^{*} p<0.1,{ }^{*+} p<0.01,{ }^{* * *} p<0.001$ 


\section{Discussion and Conclusions}

\subsection{Conclusions}

This study has enriched scholarly knowledge of customer evaluation of and satisfaction with hotels designing AI-enabled hospitality services, by exploring and analyzing if and to what extent mechanical Artificial Intelligence - embedded in hospitality service robots - influences consumers' evaluation of AI-enabled hotel service interactions. More specifically, we innovatively deployed online reviews analytics to understand if the presence of mechanical AIrelated text in online reviews has an impact on customers' e-WOM valence across 19 leading international hotels (based in three continents) that have integrated mechanical AI, in the guise of service robots, into their operations. Accordingly, we extended the nascent research stream revolving around customers' perceptions and evaluation of service robots (Rodriguez-Lizundia et al., 2015; Tung and $\mathrm{Au}, 2018, \mathrm{Yu}, 2018$ ). Our study is unique as it leverages online review analytics to capture if and how AI-enabled hospitality service interactions influence customer satisfaction, in the guise of e-WOM valence, in online settings. We find that the presence of mechanical AI-related text (text related to service robots) in online reviews (ORs) influences positively e-WOM valence. Hotel guests writing ORs explicitly mentioning their interactions with the service robots seem to be more prone to associate high online ratings to their ORs. The presence of the robot's proper name (e.g., Alina, Wally) in the online review moderates positively the positive effect of mechanical AI-related text on online reviews ratings.

\subsection{Theoretical implications}

This study contributes to a wide range of research streams, such as AI in hospitality services, data analytics, and e-WOM research. First, to our knowledge this work constitutes the first attempt to understand if and to what extent mechanical Artificial Intelligence, in the guise of hospitality service robots, influences customers' evaluation of and satisfaction with AI-enabled hospitality service interactions. By addressing the recent call for more investigation on customers' perceptions of robotics in hospitality and tourism settings (Ivanov et al., 2019; Tussyadiah, 2020), and post-service consumption involving service robots ( $\mathrm{Lu}$ et al., 2020), we contribute to the nascent research stream focusing on hotel customers' perceptions and evaluation of service robots (Belanche et al., 2020a; Rodriguez-Lizundia et al., 2015; Tung and $\mathrm{Au}, 2018$, Yu, 2018; Zhong et al., 2020), thus conducting one of the first studies leveraging online review analytics to capture if and how AI-enabled hospitality service interactions influence customers' evaluations and satisfaction in online settings. The underlying mechanism 
bringing online users to evaluate positively hotel service robots after the service interaction is underpinned by the Expectation-Confirmation Theory (Oliver1980). This complements the findings of recent conceptual research that has emphasized that robots inject elements of entertainment into hospitality services (Ivanov and Webster, 2019) thus making the experience even more enjoyable, compelling, appealing and memorable (Pine and Gilmore, 1998). This contribution also complements and corroborates recent empirical research that has found that hotel service robots are a major driver of enhanced customer experience (Tung and $\mathrm{Au}, 2018$ ) and influence customer perceived behavior at a number of levels including purchase intentions (Zhong et al., 2020). Second, this is virtually the first study addressing how the presence of mechanical AI-related text in online reviews has an impact on customers' e-WOM valence. This constitutes a significant contribution to, and extension of e-WOM literature in marketing (e.g., Rosario et al., 2016), and hospitality (e.g., Cantallops and Salvi, 2014; Litvin et al., 2008). Interestingly, it seems that online hotel reviewers are increasingly aware of hotel robots and therefore this translates into an online customers' discourse that not only is positively correlated with online review ratings, but also related to a non-standard attribute of a hotel service experience: the presence of AI-enabled technology in hospitality services. This seems to put to test and empirically corroborate the robustness of the concept of online robotic discourse (Borghi and Mariani, 2020) which has been recently introduced to aid researchers to monitor the diffusion and adoption of service robots over time. In this paper we show that the concept - and the deriving construct - can be leveraged also to get to know more about hotel guests' satisfaction with mechanical AI in general and service robots in particular.

Third, while most of the literature in service interactions and more specifically in hospitality service interactions (e.g., Magnini and Honeycutt, 2005) focuses on the importance for service providers and employees to recall customers' names, we expand the nascent research stream suggesting that the proper name of service frontline employees and service providers can make a difference in terms of customers' revisit intention (e.g., Kim and Baker) as well as customer satisfaction. Accordingly, mechanical AI (i.e., robots') name recall can play a critical role in enhancing customer satisfaction with mechanical AI, the underlying mechanism being that proper names can be means of building rapport and service relationship (Wirtz et al., 2018) which go far beyond mere service interactions (Gutek et al., 1999) and are critical to maximize customer satisfaction and service excellence. If we interpret proper names as human features, then our work might be seen as an extension of studies that have suggested that endowing robots with human features improves their capability to build a meaningful relationship with service customers. 
Fourth, we innovatively propose that, in the digital economy, consumers' satisfaction with non-standard attributes such as mechanical AI, in the guise of service robots, can be captured through Big Data Analytics from user generated content data in the form of large volumes of online consumer reviews. For instance, this study gathered 49,209 reviews. Without a BDA approach to the collection and analysis of OR data, this would have not been possible. BDA are therefore essential to discover more about contemporary online customers (Balducci and Marinova, 2018) and generalize the findings beyond national contexts. This adds to extant research that has explored the value and use of Big Data in multiple business sectors, including hospitality and tourism (Li et al., 2018).

Fifth, while so far most of the research on AI in hospitality service has leveraged experiments (lab and observational) and survey data, we believe that our approach to studying mechanical AI might pave the way to further strengthening the juxtaposition of consumer panels to big data from UGC. This certainly addresses recent calls (e.g., Berger et al., 2020; Van Auken, 2015) for more research adopting BDA to shed light on customer's perceptions and behavior.

Last, this study innovatively builds a joined-up body of knowledge fusing the nascent research stream focusing on hotel customers' perceptions and evaluation of service robots (Rodriguez-Lizundia et al., 2015; Tung and Au, 2018, Yu, 2018), the research line on e-WOM drivers of OR ratings (Cantallops and Salvi, 2014) in hospitality, and the research stream pertaining to UGC and customer behavior (Balducci and Marinova, 2018; Van Auken, 2015), with the result of gaining new knowledge on the relationship between AI-enabled hospitality services and e-WOM valence.

\subsection{Practical implications}

By capturing the impact of robots-related text in ORs on consumers' e-WOM valence, we generate practical knowledge in relation to OR valence, that not only represents a proxy of customer satisfaction (Engler et al., 2015), but also an important signal of service quality for online review readers. Therefore, we have developed a set of practical implications for hotel managers as well as OR platform' managers and developers.

As far as hotel managers are concerned, first we suggest that the integration of mechanical AI, in the guise of service robots, into their operations seems to be well received by hotel customers. Therefore, hotels might seriously ponder and evaluate the possibility to introduce service robots to pursue a cost-effective service excellence strategy (Wirtz and 
Zeithalm, 2018) to simultaneously enhance customer satisfaction and contain labour costs. However, as suggested by recent studies (Kuo et al., 2017), any investment in robots should be strategically evaluated in light of the desired brand image.

Second, as our analysis finds that hotel guests recalling the proper name of the robots are more likely to express a superior evaluation of the service, hotel managers should put attention in the way they name their robots. Easy to remember and short names (e.g., Alina, Wally) are particularly effective as they can be more easily recalled by hotel guests, thus amplifying customers' positive remembrances and reactions. Moreover, when more than one robot is employed in the hotel, the presence of an easy and distinctive proper name might allow managers (and customers) to distinguish robots easily and allow ad hoc intervention and changes on those robots that for some reasons underperformed during the human-robot interaction. Relatedly, while currently it seems that some hotels deploy generic and non-human names for their robots (e.g., Pepper), while others develop proper (human) names, hospitality practitioners should develop tailored strategies to name their robots (such as using human-like names) that might make the robot more likable and conducive to higher levels of customer satisfaction.

Third, as service robots are positively evaluated by customers, hotel managers should communicate more explicitly, both off- and on-line on multiple channels including social media and company website, their initiatives and investments in AI in general and service robots in particular. This might drive bookings and reservations from online consumers that have an interest in (or a passion for) digital technology: overall this might ultimately translate into higher revenues from this segment of customers. However, communicating with too much emphasis AI-related features of the hotel service might be potentially detrimental as techies might have come across a positive appraisal of a hotel deploying service robots and therefore might form high expectations before the hotel experience consumption. In this case, overcommunicating might become a double-edged sword and therefore managers should make sure not to overpromise or overstate their technological attributes.

Fourth, hotel managers might invest in educating their non tech savvy customers to understand and appreciate AI technology. This implies that robots should not be left in a corner of the hotel, as observed by the authors in some hotels where robots were not effectively integrated into the overall service design. On the contrary, they should be encapsulated into the design of the overall hospitality service experience (Zomerdijk and Voss, 2010), and possibly empower the service experience by injecting entertainment into hospitality service experiences (Ivanov et al., 2019), thus making them for pleasant. This resonates with the 
recommendations provided by Belanche et al. (2020c), and implies that, to generate meaningful and compelling mechanical AI-enabled service interactions, hotel managers should pay attention to the correct design, customer characteristics and the service interaction (or service encounter) characteristics which might enhance the acceptance and adoption of robots themselves (Belanche et al., 2020b; Pillai et al., 2021).

Fifth, as there might be customer segments that are less into technologies and less interested in service robots, those hotels that have already made considerable investment in robots might find it useful to activate educational initiatives and even edutainment initiatives (Pine and Gilmore, 1998) to help the non techies to develop awareness and interest in service robots. This might help the most technologically oriented hotels to spread the cost of AI investment.

Last, as the lockdown measures undertaken and implemented worldwide by a number of governments at the national and local level to face the COVID-19 pandemic have encouraged hotels to embrace social distancing measures, we envision that adopting service robots might not only respond to the pandemic emergency and the social distance requirements (Zeng et al., 2020), but also be transformed into an opportunity to engage more effectively with the customers.

In relation to platform managers and developers, they might contemplate creating a robotic tag - in the guise of a robot icon - that can be attached to ORs mentioning service robots to signal the presence of this specific element. The latter might help attract online consumers' attention, and most notably those customer segments that are into robots and technology (i.e., techy consumers). Secondly, platform developers could offer a filter enabling online consumers and Internet users to rank ORs based on the extent to which robots are featured in their text. This might facilitate prospective hotel customers' information seeking and processing in the pre-purchase phase and eventually boost techies' reservation intentions. Third, platform developers might design and build a new service attribute, that might be tentatively named "service robots", to be added to the traditional set of dimensions that usually characterizes a property (e.g., value, cleanliness, location). This could help OR platforms to generate more punctual insights on consumers' perceptions of mechanical AI in the guise of service robots. Accordingly, this added platform feature might translate into increased reservations for the techy segments. 


\subsection{Limitations and future research}

This research is not without limitations. Firstly, although we considered a relevant number of hotels offering AI-enabled services across multiple cities in three different continents, future research could broaden our study including a wider set of relevant destinations in Europe which to a certain extent is lagging behind America and Asia in terms of incorporating mechanical AI into hotels' operations. Second, while our study focused only on TripAdvisor, further research might source online review data from different platforms including online travel agencies like Booking (Mariani and Borghi 2018). In general, multiand cross-platform studies including multiple platforms are welcome. Third, future studies might take into account further moderation effects and explore how the direct effect of the presence of mechanical AI on online ratings is moderated by factors such as location (continent) hotel category, type of task performed by the robot, travel group. Fourth, future research might look in a more granular way at the moderating effect of the proper names on the relationship between the presence of $\mathrm{AI}$ and online review ratings: this might be pursued by means of experiments comparing situations whereby no name, a non-human and a human name are given to the robots. Fifth, to capture in a more nuanced way the measured effects, mixed methods triangulating both quantitative evidence from online reviews and qualitative appraisals of service robots on customers' behaviors are encouraged: this might allow to juxtapose different types of data covering both perceptions and behaviors. Last, while we were able to control for the effect of the proper name of the robot on online review ratings, future research might also look at the differentiated impact of gender, i.e., male vs. female robots' proper names, on customer satisfaction in the guise of online ratings. 


\section{REFERENCES}

Agresti, A. (2010), Analysis of ordinal categorical data, John Wiley \& Sons, Hoboken, NJ.

Balducci, B. and Marinova, D. (2018). "Unstructured data in marketing", Journal of the Academy of Marketing Science, Vol.46 No.4, pp.557-590.

Belanche, D., Casaló, L.V. and Flavián, C. (2020a). "Frontline robots in tourism and hospitality: service enhancement or cost reduction?", Electronic Markets, article number 10.1007/s12525-020-00432-5.

Belanche, D., Casaló, L.V. and Flavián, C. (2020b), "Customer's Acceptance of Humanoid Robots in Services: The Moderating Role of Risk Aversion”, Smart Innovation, Systems and Technologies, Vol.167, pp.449-458.

Belanche, D., Casaló, L.V., Flavián, C. and Schepers, J. (2020c), "Service robot implementation: a theoretical framework and research agenda", The Service Industries Journal, Vol.40 No. 3-4, pp.203-225.

Belanche, D., Casaló, L.V., Flavián, C. and Schepers, J. (2020d), "Robots or frontline employees? Exploring customers' attributions of responsibility and stability after service failure or success", Journal of Service Management, Vol.31 No.2, pp.267-289

Berger, J., Humphreys, A., Ludwig, S., Moe, W.W., Netzer, O. and Schweidel, D.A. (2020), Uniting the tribes: Using text for marketing insight. Journal of Marketing, Vol. 84 No. $1, \mathrm{pp} .1-25$.

Bi, J.W., Liu, Y., Fan, Z.P. and Zhang, J. (2020), "Exploring asymmetric effects of attribute performance on customer satisfaction in the hotel industry", Tourism Management, Vol.77, article number 104006.

Bi, J.W., Liu, Y., Fan, Z.P.and Zhang, J. (2019), Wisdom of crowds: Conducting importanceperformance analysis (IPA) through online reviews. Tourism Management, Vol.70, pp.460-478.

Blal, I. and Sturman, M.C. (2014), "The differential effects of the quality and quantity of online reviews on hotel room sales", Cornell Hospitality Quarterly, Vol.55 No.4, pp.365-375.

Booij, G. (2012). The grammar of words: An introduction to linguistic morphology, Oxford University Press, Oxford, UK.

Borghi, M. and Mariani, M. (2020), "Service robots in online reviews: online robotic discourse", Annals of Tourism Research, article number 103036.

Bowen, J. and Morosan, C. (2018), "Beware hospitality industry:The robots are coming", Worldwide Hospitality and Tourism Themes, Vol.10 No.6, pp.726-733.

Cantallops, A.S. and Salvi, F. (2014), "New consumer behavior: A review of research on eWOM and hotels", International Journal of Hospitality Management, Vol.36, pp.4151.

Cezar, A. and Ögüt, H. (2016), "Analyzing conversion rates in online hotel booking", International Journal of Contemporary Hospitality Management, Vol.28 No.(2), pp.286-304.

Chu, S. C. and Kim, Y. (2011), "Determinants of consumer engagement in electronic word-ofmouth (eWOM) in social networking sites", International journal of Advertising, Vol.30 No.1, pp.47-75. 
Colby, C.L., Mithas, S. and Parasuraman, A. (2016), "Service Robots: How Ready are Consumers to Adopt and What Drives Acceptance?", The 2016 Frontiers in Service Conference, Bergen, Norway.

Davenport, T. and Ronanki, R. (2018), "Artificial Intelligence for the Real World", Harvard Business Review. Vol.January-February 2018.

Dellarocas, C., Gao, G. and Narayan, R. (2010), "Are consumers more likely to contribute online reviews for hit or niche products?". Journal of Management Information Systems, Vol.27 No.2, pp.127-158.

Engler, T.H., Winter, P. and Schulz, M. (2015), "Understanding online product ratings: A customer satisfaction model", Journal of Retailing and Consumer Services, Vol.27, pp.113-120.

Forman, C., Ghose, A. and Wiesenfeld, B. (2008), "Examining the relationship between reviews and sales: The role of reviewer identity disclosure in electronic markets", Information systems research, Vol.19 No.3, pp.291-313.

Fosso Wamba, S., Akter, S., Edwards, A., Chopin, G. and Gnanzou, D. (2015), "How big data can make big impact: Findings from a systematic review and a longitudinal case study", International Journal of Production Economics, Vol.165, pp.234-246.

Gao, B., Li, X., Liu, S. and Fang, D. (2018), "How power distance affects online hotel ratings: The positive moderating roles of hotel chain and reviewers' travel experience", Tourism Management, Vol.65, pp.176-186.

Gartner (2019). "Gartner Top 10 Strategic Technology Trends for 2019”. Available at: https://www.gartner.com/smarterwithgartner/gartner-top-10-strategic-technologytrends-for-2019/ (accessed 20th June, 2020).

Gutek, B. A., Bhappu, A. D., Liao-Troth, M. A., and Cherry, B. (1999), "Distinguishing between service relationships and encounters", Journal of Applied Psychology, Vol. 84 No.2, pp.218-233

Haenlein, M. and Kaplan, A. (2019), "A brief history of artificial intelligence: On the past, present, and future of artificial intelligence", California Management Review, Vol. 61 No.4, pp.5-14.

Hennig-Thurau, T., Gwinner, K.P., Walsh, G. and Gremler, D.D. (2004), "Electronic word-ofmouth via consumer-opinion platforms: What motivates consumers to articulate themselves on the Internet?", Journal of Interactive Marketing, Vol.18 No.1, pp.38-52.

$\mathrm{Hu}$, Y.and Li, X. (2011), "Context-dependent product evaluations: an empirical analysis of internet book reviews". Journal of Interactive Marketing, Vol.25 No.3, pp.123-133.

Huang, M. H. and Rust, R.T. (2020), "Engaged to a Robot? The Role of AI in Service”, Journal of Service Research, article number 1094670520902266.

Huang, M.H. and Rust, R.T. (2018), “Artificial intelligence in service”, Journal of Service Research, Vol.21 No.2, pp.155-172.

Inversini, A., Marchiori, E., Dedekind, C. and Cantoni, L. (2010), "Applying a conceptual framework to analyze online reputation of tourism destinations", in Gretzel, U., Law, R., \& Fuchs, M. (Ed.s), Information and Communication Technologies in Tourism 2010, Vienna, Springer, pp.321-332. 
Ivanov, S., Gretzel, U., Berezina, K., Sigala, M. and Webster, C. (2019), "Progress on robotics in hospitality and tourism: a review of the literature", Journal of Hospitality and Tourism Technology, Vol.10 No.4, pp.489-521.

Ivanov, S., Webster, C. and Berezina, K. (2017), "Adoption of robots and service automation by tourism and hospitality companies", Revista Turismo \& Desenvolvimento, Vol.27/28, pp.1501-1517.

King, R.A., Racherla, P. and Bush, V.D. (2014), "What we know and don't know about online word-of-mouth: A review and synthesis of the literature", Journal of Interactive Marketing, Vol.28 No.3, pp.167-183.

Kim, K., and Baker, M. A. (2017), "The impacts of service provider name, ethnicity, and menu information on perceived authenticity and behaviors", Cornell Hospitality Quarterly, Vol.58 No.3, pp. 312-318.

Kuo, C.M., Chen, L.C. and Tseng, C.Y. (2017), "Investigating an innovative service with hospitality robots", International Journal of Contemporary Hospitality Management, Vol.29 No.5, pp.1305-1321.

Laney, D. (2001), “3D Data Management: Controlling Data Volume, Velocity and Variety”. META Group Research Note, No. 6. Available at: https://blogs.gartner.com/douglaney/files/2012/01/ad949-3D-Data-Management-Controlling-Data-Volume-Velocityand-Variety.pdf (accessed 16th June, 2020).

Li J., Xu L., Tang L., Wang S. and Li L. (2018), "Big data in tourism research: A literature review", Tourism Management, Vol.68, pp.301-323.

Litvin, S.W., Goldsmith, R.E. and Pan, B. (2008), "Electronic word-of-mouth in hospitality and tourism management", Tourism Management, Vol.29 No.3, pp.458-468.

Lu, V.N., Wirtz, J., Kunz, W.H., Paluch, S., Gruber, T., Martins, A. and Patterson, P.G. (2020), "Service robots, customers and service employees: what can we learn from the academic literature and where are the gaps?". Journal of Service Theory and Practice, Vol.30 No.3, pp.361- 391.

Ludwig, S., de Ruter, K., Friedman, M., Bruggen, E. C.,Wetzels, M. and Pfann, G. (2013), "More than words: The influence of affective content and linguistic style matches on line reviews on conversion rates", Journal of Marketing, Vol.77, pp.87-103.

Magnini, V.P. and Honeycutt Jr, E.D. (2005), "Face recognition and name recall: training implications for the hospitality industry", Cornell Hotel and Restaurant Administration Quarterly, Vol.46 No.1, pp.69-78.

Mariani, M.M. and Borghi, M. (2018), "Effects of the Booking. com rating system: Bringing hotel class into the picture", Tourism Management, Vol.66, pp.47-52.

Mariani, M.M. and Borghi, M. (2019), "Industry 4.0: A bibliometric review of its managerial intellectual structure and potential evolution in the service industries", Technological Forecasting and Social Change, Vol.149, article number 119752.

Mariani, M.M., Baggio, R., Fuchs, M. and Höpken, W. (2018), "Business Intelligence and Big Data in Hospitality and Tourism: A Systematic Literature Review", International Journal of Contemporary Hospitality Management, Vol.30 No.10, pp.3514-3554. 
Mariani, M., Di Fatta, G., and Di Felice, M. (2018), "Understanding customer satisfaction with services by leveraging big data: the role of services attributes and consumers' cultural background", IEEE Access, 7, 8195-8208.

Mariani, M. (2019), "Big data and analytics in tourism and hospitality: a perspective article", Tourism Review, Vol. 75 No. 1, pp. 299-303.

Mariani, M.M., Borghi, M. and Kazakov, S. (2019), "The role of language in the online evaluation of hospitality service encounters: An empirical study", International Journal of Hospitality Management, Vol.78, pp.50-58.

Mariani, M. M., Borghi, M., and Gretzel, U. (2019), "Online reviews: differences by submission device”, Tourism Management, Vol. 70, pp. 295-298.

Mariani, M. and Predvoditeleva, M. (2019), "How do online reviewers' cultural traits and perceived experience influence hotel online ratings?", International Journal of Contemporary Hospitality Management, Vol.31 No.12, pp.4543-4573.

Mariani, M. and Fosso Wamba, S. (2020), "Exploring how consumer goods companies innovate in the digital age: The role of big data analytics companies", Journal of Business Research, Vol. 121, pp.338-352.

Mariani, M. and Borghi, M. (2020), "Online Review Helpfulness and Firms' Financial Performance: An Empirical Study in a Service Industry", International Journal of Electronic Commerce, Vol. 24 No. 4, pp. 421-449.

Mills, M. (2018), "There are robots on staff at this San Gabriel hotel”, San Gabriel Valley Tribune, available at: https://www.sgvtribune.com/2018/08/28/there-are-robots-onstaff-at-this-san-gabriel-hotel/ (accessed 20 October 2020)

Munzel, A. (2016), "Assisting consumers in detecting fake reviews: The role of identity information disclosure and consensus", Journal of Retailing and Consumer Services, Vol.32, 96-108.

Oliver, R.L. (1980), "A cognitive model of the antecedents and consequences of satisfaction decisions", Journal of marketing research, Vol.17 No.4, pp.460-469.

Phillips, P., Antonio, N., de Almeida, A. and Nunes, L. (2020), "The influence of geographic and psychic distance on online hotel ratings", Journal of Travel Research, Vol.59 No.4, pp.722-741.

Pillai, R., Sivathanu, B., Mariani, M., Rana, N. P., Yang, B., \& Dwivedi, Y. K. (2021). Adoption of AI-empowered industrial robots in auto component manufacturing companies. Production Planning \& Control, 1-17. DOI: $10.1080 / 09537287.2021 .1882689$

Pine, B.J. and Gilmore, J.H. (1998), "Welcome to the experience economy”, Harvard business review, Vol.76, pp.97-105.

Rodriguez-Lizundia, E., Marcos, S., Zalama, E., Gomez-García-Bermejo, J. and Gordaliza, A. (2015), "A bellboy robot: study of the effects of robot behaviour on user engagement and comfort", International Journal of Human-Computer Studies, Vol.82, pp.83-95.

Rosario, A.B., Sotgiu, F., De Valck, K. and Bijmolt, T.H.A. (2016), "The effect of electronic word of mouth on sales: A meta-analytic review of platform, product, and metric factors", Journal of Marketing Research, Vol.53 No.3, pp.297-318. 
Rüßmann, M., Lorenz, M., Gerbert, P., Waldner, M., Justus, J., Engel, P. and Harnisch, M. (2015), "Industry 4.0: the future of productivity and growth in manufacturing industries", Boston Consulting Group, No.9, 2015, Available at: https://www.bcg.com/publications/2015/engineered_products_project_business_indus try 4 future productivity_growth_manufacturing industries.aspx.

Sridhar, S. and Srinivasan, R. (2012), "Social influence effects in online product ratings", Journal of Marketing, Vol.76 No.5, pp.70-88.

Stock, R.M. and Merkle, M. (2017), “A service Robot Acceptance Model: User acceptance of humanoid robots during service encounters", 2017 IEEE International Conference on Pervasive Computing and Communications Workshops (PerCom Workshops), Kona, HI, pp.339-344.

Sun, T., Youn, S., Wu, G. and Kuntaraporn, M. (2006), "Online word-of-mouth (or mouse): An exploration of its antecedents and consequences", Journal of Computer-Mediated Communication, Vol.11 No.4, pp.1104-1127.

Titov, I. and McDonald, R. (2008), "Modeling online reviews with multi-grain topic models", in Proceedings of the 17th international conference on World Wide Web, Beijing, Association for Computing Machinery, pp.111-120.

Tung, V.W.S. and Au, N. (2018), "Exploring customer experiences with robotics in hospitality", International Journal of Contemporary Hospitality Management, Vol.30 No.7, pp.2680-2697.

Tung, V.W.S. and Law, R. (2017), "The potential for tourism and hospitality experience research in human-robot interactions", International Journal of Contemporary Hospitality Management, Vol.29 No.10, pp.2498-2513.

Tuomi, A., Tussyadiah, I.P. and Stienmetz, J. (2020). “Applications and implications of service robots in hospitality", Cornell Hospitality Quarterly, Article Number 1938965520923961.

Tussyadiah, I. (2020), "A review of research into automation in tourism: Launching the Annals of Tourism Research Curated Collection on Artificial Intelligence and Robotics in Tourism“, Annals of Tourism Research, Vol.81, article number 102883.

Van Auken, S. (2015), "From consumer panels to big data: An overview on marketing data development", Journal of Marketing Analytics, Vol.3 No.1, pp.38-45.

Wirtz, J. and Zeithaml, V. (2018), "Cost-effective service excellence", Journal of the Academy of Marketing Science, Vol.46, pp.59-80.

Wirtz, J., Patterson, P.G., Kunz, W.H., Gruber, T., Lu, V.N., Paluch, S. and Martins, A. (2018), "Brave new world: Service robots in the frontline", Journal of Service Management, Vol.29 No.5, pp.907-931.

$\mathrm{Xu}, \mathrm{Y}$., Li, H., Law, R. and Zhang, Z. (2020), "Can receiving managerial responses induce more user reviewing effort? A mixed method investigation in hotel industry", Tourism Management, Vol.77, 103982.

Yang, Y., Park, S. and Hu, X. (2018), "Electronic word of mouth and hotel performance: a meta-analysis", Tourism Management, Vol.67, pp.248-260.

You, Y., Vadakkepatt, G.G. and Joshi, A.M. (2015), “A Meta-analysis of Electronic Word-ofmouth Elasticity”, Journal of Marketing, Vol. 79 No. 2, pp.19-39. 
Yu, C.-E. (2018), "Perceptual differences toward humanlike robots and humans in service: individualist versus collectivist cultures", in Mauer, C., \& Neuhofer, B. (Ed.s), ISCONTOUR 2018 Tourism Research Perspectives:Proceedings of the International Student Conference in Tourism Research, pp.323-332.

Zeng, Z., Chen, P.-J. and Lew, A.A. (2020), "From high-touch to high-tech: COVID-19 drives robotics adoption", Tourism Geographies, Vol.22 No.3, pp.724-734.

Zhang, Z., Zhang, Z. and Yang, Y. (2016), "The power of expert identity: How websiterecognized expert reviews influence travelers' online rating behavior", Tourism Management, Vol.55, pp.15-24.

Zhao, Y., Xu, X. and Wang, M. (2019), "Predicting overall customer satisfaction: Big data evidence from hotel online textual reviews", International Journal of Hospitality Management, Vol.76, pp.111-121.

Zhong, L., Sun, S., Law, R. and Zhang, X. (2020), "Impact of robot hotel service on consumers' purchase intention: a control experiment", Asia Pacific Journal of Tourism Research, Vol. 25 No.7, pp.780-790.

Zhou, L., Ye, S., Pearce, P. L. and Wu, M.Y. (2014), "Refreshing hotel satisfaction studies by reconfiguring customer review data", International Journal of Hospitality Management, Vol.38, pp.1-10.

Zhu, F. and Zhang, X. (2010), "Impact of online consumer reviews on sales: The moderating role of product and consumer characteristics", Journal of Marketing, Vol.74 No.2, pp.133-148.

Zomerdijk, L.G. and Voss, C.A. (2010), "Service design for experience-centric services", Journal of Service Research, Vol.13 No.1, pp.67-82. 